\title{
Experimental results of the tribology of aluminum measured with a pin-on-disk tribometer: Testing configuration and additive effects
}

\author{
S. M. H. AHMER ${ }^{1, *}$, L. S. JAN ${ }^{1}$, M. A. SIDDIG ${ }^{2}$, S. F. ABDULLAH ${ }^{3}$ \\ ${ }^{1}$ Department of Physics, GS Faculty, Yanbu University College, Yanbu al Sinayiah 41912, Kingdom of Saudi Arabia \\ ${ }^{2}$ Department of Physics, Faculty of Science and Technology, al Neelain University, Khartoum 11111, Sudan \\ ${ }^{3}$ Mechanical Engineering Department, UNITEN, Kajang 43009, Malaysia \\ Received: 23 December 2015 / Revised: 03 March 2016 / Accepted: 18 April 2016 \\ (C) The author(s) 2016. This article is published with open access at Springerlink.com
}

\begin{abstract}
The friction coefficient, wear rate, and wear coefficient of the aluminum metal surface were measured at room temperature $(\approx 300 \mathrm{~K})$ with a pin-on-disk machine at a fixed load of $196.2 \mathrm{~N}$. Two different testing configurations were adopted: (1) aluminum pin vs. Helix oil-on-steel disk (AHS) and (2) aluminum pin vs. $10 \%$ Polytron plus $90 \%$ helix oil-on-steel disk (APS). In the AHS configuration, the wear of the aluminum surface was found to be approximately $70 \mu \mathrm{m}$; however, in the APS configuration the wear dropped to $20 \mu \mathrm{m}$, revealing a marked decrement of one-third of the wear of aluminum. The volume wear rate of the metal in the unaided Helix oil was estimated to be $1.28 \times 10^{-3} \mathrm{~mm}^{3} / \mathrm{min}$. The additive minimized the volume wear rate of the aluminum metal by orders of magnitude to $6.08 \times 10^{-5} \mathrm{~mm}^{3} / \mathrm{min}$. Similarly, the wear coefficient of the aluminum pin, calculated in the AHS configuration, rendered a value of $1.27 \times 10^{-10} \mathrm{~m}^{2} / \mathrm{N}$. In the APS configuration, the same parameter was $4.22 \times 10^{-11} \mathrm{~m}^{2} / \mathrm{N}$, that is to say, an order of magnitude lower than the preceding value. The observed coefficient of friction for aluminum is 0.012 in Helix oil and falls to a remarkably lower value of 0.004 through the Polytron additive. The experimental findings demonstrate that Polytron additive substantially lessens the wear of the aluminum surface; in effect, the wear coefficient and the wear rate decline linearly. This singularity may be linked to the ability of Polytron to impregnate the crystal structure of the metal due to its ionic character and the consequent adherence to the metallic surface as a hard surface layer.
\end{abstract}

Keywords: antiwear; Polytron additive; aluminum metal; lubrication; friction

\section{Introduction}

Beginning with the first mechanical device, lubrication has been an essential design parameter for any mobile parts involved in machinery, mechanical tools, and transport means. A variety of materials, in the forms of gas, liquid, or solid, were interposed between two surfaces in order to improve the smoothness of relative movement and to prevent damages to the surfaces. It was noticed that the variation of friction and wear

\footnotetext{
* Corresponding author: S. M. H. AHMER.
}

E-mail: ahmers@rcyci.edu.sa rate depends on various interfacial conditions such as normal load, geometry, relative surface motion, sliding speed, surface roughness of the rubbing surfaces, type of material, system rigidity, temperature, relative humidity, lubrication, and vibration [1-13]. Nevertheless, for the alteration of friction and wear rate, sliding speed and normal load are considered to be of paramount importance. Similarly, it has been found that the friction force is a function of both velocity and time of contact and that the coefficient of friction may be very low for very smooth surfaces and/or at loads in the micro- to nano-newton range [14, 15]. Therefore, some authors have explored lubricants and have 
proposed them to be potential mediators for reducing friction and wear of the mating surfaces [16-18]. However, in applications like automobile engines and complex machinery, the base lubricant is not sufficient to give a long life to the sliding or mating parts. The usual solution is the addition of a relatively small amount of certain additive compounds that provide a significant improvement of the base oil properties with regard to either oxidative degradation or tribological and other performance characteristics [19-25]. Most of the additives comprise polar functional groups and belong to various classes of organic or organometallic compounds. In general, the triboactive additives contain active elements (or combinations thereof) such as phosphorous (P), sulphur (S), chlorine $(\mathrm{Cl})$, zinc $(\mathrm{Zn})$, nitrogen $(\mathrm{N})$, tungsten $(\mathrm{W})$, and carbon (C). A recent trend is the addition of nanoparticles to various lubricants. These components are capable of forming protective tribological inorganic or comparable layers on frictional surfaces due to reactions with the constituent material (typically iron and its alloys) [26-34]. The above-mentioned components and their nanocounter parts are often added up to $5 \mathrm{wt} \%$ as monomeric antiwear and extreme pressure agents for the prevention of serious metal surface depletion. In many applications the wear reduction mechanism and quantitative analysis of the additives are not well known and a thorough exploration is still inescapable. A literature survey reveals that research has been done on various materials and conflicting views have been advanced by different authors in favor of their results. However, research on an unusual and elusive additive known as Polytron is highly scarce; therefore, to the best of our knowledge the experimental work presented in this article seems to be the first of its kind. In this research study, this uncommon antiwear additive Polytron has been selected for an investigation to assess its wear reduction and friction minimization strategy. As such, the research dictates a scientific determination to understand the interaction mechanism of Polytron with metal substrates as well as the consequent smoothening and lubrication of the interacting surfaces. Polytron is an oily fluid mixture of petroleum-based chemicals mixed with oxidation inhibitors and detergent chemicals, which at ambient pressure and temperature is a stable grease in stark contrast to the conventional lubricants. Polytron additives, being petroleum based, contain no solid particles and are compatible with all the lubricants available in the market. Polytron comprises $80 \%$ para and 20\% meta Polytron. The specialized Polytron metal treatment concentrate (MTC) is polarized, and it is attracted to metal surfaces and develops a durable polished-like microscopic layer through metallurgical process that can resist wear, extreme pressure, and excessive temperature. As such, this analysis was prompted to understand the effect of the Polytron additive on the friction and wear behavior of aluminum metal sliding against stainless steel. It can be suggested that Polytron is an effective antiwear additive in the Helix base oil and can intrinsically reduce friction and wear by orders of magnitude. Realistically, Polytronlubricated systems can deliver consistent performance for longer than the anticipated duty cycle of the machinery and protect the system from wear and premature failures.

The aim of this research study is to bring out the second phase of our experimental outcomes regarding the Polytron additive in the Helix lubricant to clearly understand the impact of the reaction film of Polytron on the rubbing surfaces of the metals and the ensuing antiwear protection capability. Introductory effects with reference to the Polytron additive in the Helix lubricant can be found elsewhere $[35,36]$.

\section{Materials and methods}

\subsection{Experimental apparatus}

For recording the data of the wear tests, we used the pin-on-disk tribotester (TR-20LE) (Ducom Instruments, India). The apparatus was enclosed in a plexiglass box that could be purged with dry air or nitrogen. A hygrometer (ZEAL, England) was used to measure the relative humidity of the air in the chamber. A tachometer was used to measure the revolutions per minute of the rotating shaft. The force of friction was recorded as a function of time and measured by a piezoelectric transducer. A basic outline of the pinon-disk device is given in Fig. 1. The device comprises a pin that can slide on a rotating horizontal surface (disk). The circular steel disk is fixed on a rotating plate (table) that has a long vertical shaft welded from the bottom surface of the rotating plate. The shaft 

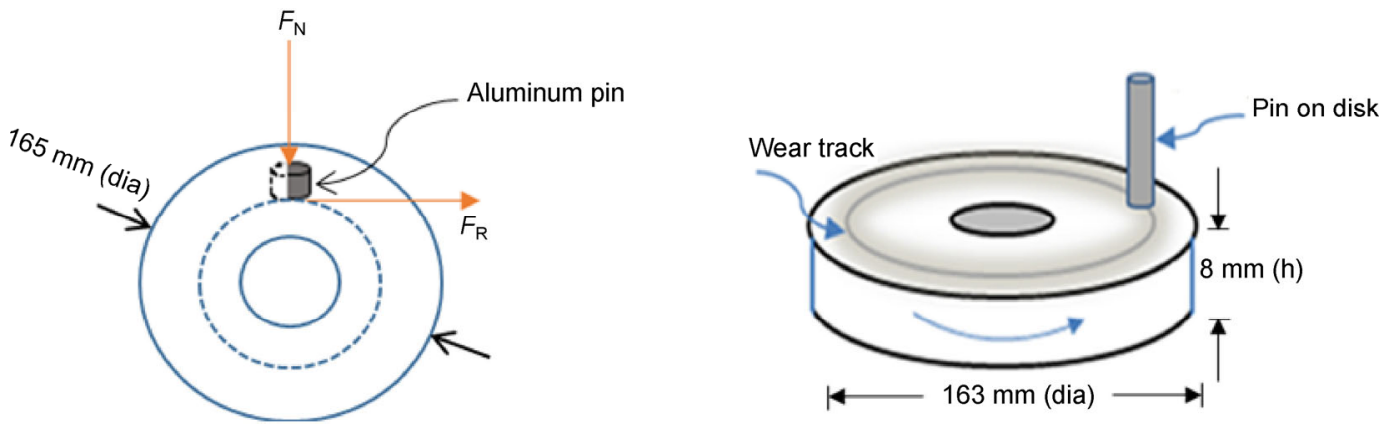

Fig. 1 Sketch of the pin-on-disk. The dimensions of the pin were $32 \mathrm{~mm}$ (length) by $10 \mathrm{~mm}$ (diameter); the dimensions of the disk were $165 \mathrm{~mm}$ (diameter) by $8 \mathrm{~mm}$ (height).

passes through three close-fitted bush-bearings that are rigidly fixed with three square plates in such a way that the shaft can move only axially and any that radial movement of the rotating shaft is restrained by the bush. In the sketch, $F_{\mathrm{N}}$ stands for the normal force (load) on the aluminum pin despite the fact that $F_{R}$ represents the resistive force (friction) that arises from the sliding contact of the aluminum pin on the steel disk. Essential information vis-à-vis stainless steel disk and aluminum pin are enumerated in Tables 1

Table 1 Specification of the stainless steel disk (SUS304).

\begin{tabular}{ll}
\hline \multicolumn{1}{c}{ Property } & \multicolumn{1}{c}{ Standard value } \\
\hline Disk dimensions & $165 \mathrm{~nm}($ dia $) \times 8 \mathrm{~mm}(\mathrm{~h})$ \\
Counter bore & M5 holes from bottom $\times 4$ nos \\
Counter bore & M5 holes from top $\times 4$ nos \\
Holes & M4 tapped holes $\times 2$ nos \\
Mechanical properties & \\
Density & $8,000\left(\mathrm{~kg} / \mathrm{m}^{3}\right)$ \\
Young's modulus & $190(\mathrm{GPa})$ \\
Tensile strength & $520(\mathrm{GPa})$ \\
Yield strength & $420(\mathrm{GPa})$ \\
Poisson's ratio & $0.27-0.30$ \\
Hardness (Brinell hardness) & $88(\mathrm{HB})$ \\
Chemical composition & \\
Carbon (C) & $\leqslant 0.08 \%$ \\
Silicon (Si) & $\leqslant 1.00 \%$ \\
Manganese (Mn) & $\leqslant 2 \%$ \\
Phosphorus (P) & $\leqslant 0.045 \%$ \\
Sulphur (S) & $\leqslant 0.30 \%$ \\
Nickel (Ni) & $\leqslant 8 \%-10.5 \%$ \\
Chromium (Cr) & \\
\hline &
\end{tabular}

and 2. Moreover, the data sheets for the Helix oil and Polytron additive can be envisaged from Tables 3 and 4 . One may discern from Table 4 that Polytron is

Table 2 Compositional analysis and mechanical properties of aluminum-silicon alloy pin (A390) [37].

\begin{tabular}{lcc}
\hline Chemical composition & $\begin{array}{c}\text { Minimum } \\
\text { (by weight) }\end{array}$ & $\begin{array}{c}\text { Maximum } \\
\text { (by weight) }\end{array}$ \\
\hline Silicon & $0.4 \%$ & $0.8 \%$ \\
Iron & No & $0.7 \%$ \\
Copper & $0.15 \%$ & $0.15 \%$ \\
Manganese & No & $0.15 \%$ \\
Magnesium & $0.8 \%$ & $1.2 \%$ \\
Chromium & $0.04 \%$ & $0.35 \%$ \\
Zinc & No & $0.25 \%$ \\
Titanium & No & $0.15 \%$ \\
Other elements no more than $0.05 \%$ each, $0.15 \%$ total \\
Remainder aluminum $95.85 \%-98.56 \%$ \\
Mechanical properties \\
Hardness \\
Density \\
Tensile strength \\
\hline
\end{tabular}

Table 3 Typical physical characteristics of shell helix oil ultra (5W-40) taken from Ref. [38].

\begin{tabular}{lcc}
\hline \multicolumn{1}{c}{ Properties } & Method & Shell helix ultra \\
\hline SAE viscosity grade & & $5 \mathrm{~W}-40$ \\
Kinematic viscosity & & \\
$@ 40{ }^{\circ} \mathrm{C} \mathrm{cSt}$ & IP 71 & 81.1 \\
$@ 100{ }^{\circ} \mathrm{C} \mathrm{cSt}$ & IP 71 & 14.5 \\
Viscosity index & IP 226 & 187 \\
Density @ $15{ }^{\circ} \mathrm{C}(\mathrm{kg} / \mathrm{L})$ & IP 365 & 0.856 \\
Flash point PMCC $\left({ }^{\circ} \mathrm{C}\right)$ & IP 34 & 206 \\
Pour point $\left({ }^{\circ} \mathrm{C}\right)$ & IP 15 & -39 \\
HTHS viscosity@ $150{ }^{\circ} \mathrm{C}(\mathrm{mPa} \cdot \mathrm{s})$ & 3.68 \\
\hline
\end{tabular}


Table 4 Data sheet of polytron taken from Ref. [39].

\begin{tabular}{lc}
\hline Physical/chemical property & Observation \\
\hline State & Liquid \\
Color & Yellowish clear \\
Smell & Odourless \\
Specific gravity & $60 / 60 \approx 1.00$ \\
Boiling point range & $>300{ }^{\circ} \mathrm{C}$ \\
Flash point & $>200{ }^{\circ} \mathrm{C}$ \\
Viscosity @ $100{ }^{\circ} \mathrm{F}$ & $\mathrm{SUS} 391$ \\
Viscosity @ $210{ }^{\circ} \mathrm{F}$ & $\mathrm{SUS} 61$ \\
Water solubility $\left(T=20{ }^{\circ} \mathrm{C}\right)$ & Low \\
Evaporation point & Higher than ether \\
\hline
\end{tabular}

marketed in a liquid state and is yellowish as well as odorless in contrast to other solid additives. Its flash and boiling points are above $200{ }^{\circ} \mathrm{C}$ and $300{ }^{\circ} \mathrm{C}$, respectively, and its solubility in water is very low. Basic information regarding the aluminum metal, steel disk, Helix oil, and Polytron were taken from Refs. [37-39].

\subsection{Experimental technique}

The experimental work was performed in the tribology laboratory of UKM at approximately $70 \%$ relative humidity and room temperature( $\approx 300 \mathrm{~K})$. The Helix base oil (Shell Helix ultra 5W-40) was supplied by the Shell Oil Company at Bandar Baru Bangi. The Polytron MTC was provided by the Malaysian association of productivity Petaling Jaya, Malaysia. Both samples were used as supplied. The solutions of the base oil Helix and the Polytron additive were prepared at ambient temperature and pressure. These solutions were then stored in brown bottles to eliminate possible light-induced degeneration. Graduated cylinders were used for the precise addition of the base lubricant and the additive. The glassware and containers used in the experiment were thoroughly rinsed with ethanol and dried in an oven for $2 \mathrm{~h}$ at $110{ }^{\circ} \mathrm{C}$. For the tribotester, we used a soft aluminum-silicon alloy (A390) as pin and stainless steel (SUS304) as the disk material. The pure aluminum pins (less than $0.1 \%$ impurities) were given a final polish with $10 \mu \mathrm{m}$ alumina and then annealed in a vacuum furnace above the recrystallization temperature and cooled slowly in order to give a uniform hardness for all of the pins so as to acquire reproducible wear measurements. The disk was lap ground and given a final polish of $60 \mu \mathrm{m} \mathrm{SiC}$. The data was obtained for separate test runs with the Helix base oil and then with Polytron (10\%) as an additive. Wear rates were calculated from the measured weight loss of a pin after rubbing for a definite time (i.e., $240 \mathrm{~min}$ ). The mass and volume of the pin were measured both before and after running the experiment. The mechanical properties of the pin before and after running the machine are presented in Tables 5 and 6 . The wear experiment was performed by sliding the aluminum pin having a hemispherical tip (diameter: $10 \mathrm{~mm}$ ) on the hardened steel disk. A fixed load of $20 \mathrm{~kg}$ was applied on the pin by a pulley system. For each run of the experiment, an unworn position of the pin and a different face of the disk was used. For the pin-on-disk experiment, we took 2,000 mL of Helix oil in a graduated cylinder. In the first instance, $100 \%$ Helix base oil was used and its volume was 2,000 mL. In the second instance, $1,800 \mathrm{~mL}(90 \%)$ base oil was mixed with $200 \mathrm{~mL}(10 \%)$ Polytron. The lubricant was applied to the disk surface at a constant flow rate of almost $0.5 \mathrm{~mL} / \mathrm{min}$ and the disk was completely covered with lubricant before running the test. The wear volume was calculated from the pin wear scar diameters. Typical wear versus time curves were obtained with Matlab software and polynomial fitted to discern the trend

Table 5 Specifics of the aluminum pin and stainless steel disk and experimental results of the wear test in the Shell Helix oil (5W-40).

\begin{tabular}{lc}
\hline \multicolumn{1}{c}{ Test parameter } & Specific/computed value \\
\hline Wear of aluminium pin & $70 \pm 0.1 \mathrm{micron}$ \\
Before the wear run & \\
Material of the wear disk & Stainless steel 304 \\
Diameter of the wear disk & $80 \mathrm{~mm}$ \\
Mass of the pin & $6.4480 \mathrm{~g}$ \\
Length of the pin & $32.00 \mathrm{~mm}$ \\
During the wear run & $500 \mathrm{rpm}$ \\
Speed of the wear disk & $14,400 \mathrm{~s} \approx 240 \mathrm{~min} \approx 4.0 \mathrm{~h}$ \\
Time allocated & $2.09 \mathrm{~m} / \mathrm{s}$ \\
Sliding speed & $30,163.2 \mathrm{~m} \approx 30.163 \mathrm{~km}$ \\
Sliding distance & \\
After the wear run & $6.4470 \mathrm{~g}$ \\
Mass of the pin & $31.981 \mathrm{~mm}$ \\
Length of the pin &
\end{tabular}


Table 6 Experimental particulars of the wear tests of aluminum pin in the Shell Helix oil (5W-40) mixed with 10\% Polytron additive.

\begin{tabular}{lc}
\hline \multicolumn{1}{c}{ Test parameter } & Specific/computed value \\
\hline Wear of aluminium pin & $20 \pm 0.1$ micron \\
Before the wear run & \\
Quantity (Helix Oil) & $196.2 \mathrm{~N}$ \\
Load & Aluminum-silicon alloy $(\mathrm{A} 390)$ \\
Material of the pin & $6.4480 \mathrm{~g}$ \\
Mass of the pin & $10.00 \mathrm{~mm}$ \\
Pin diameter & $32.00 \mathrm{~mm}$ \\
Length of the pin & $80 \mathrm{~mm}$ \\
Material of the wear disk & Stainless steel SUS 304 \\
Diameter of the wear disk & $500 \mathrm{rpm}$ \\
During the wear run & $14,400 \mathrm{~s} \approx 240 \mathrm{~min} \approx 4.0 \mathrm{~h}$ \\
Speed of the Wear Disk & $2.09 \mathrm{~m} / \mathrm{s}$ \\
Time allocated & $31.996 \mathrm{~mm}$ \\
Sliding Speed & $30,163.2 \mathrm{~m} \approx 30.163 \mathrm{~km}$ \\
Sliding Distance & \\
After the wear run & \\
Mass of the pin & \\
Length of the pin & \\
\hline
\end{tabular}

of the data points. This practice was reiterated for each solution and each condition in an independent test. A series of experiments were performed successively and the same data set was obtained from each experiment. As such, the experimental error was negligibly small in the data. To identify the extraordinary contribution of the Polytron additive in the Helix lubricant, three key tribological parameters, viz., mass wear rate, volume wear rate, and wear coefficient were calculated. They are defined by Eqs. (1), (2), and (3), respectively. The quantitative values of these parameters are listed in Table 7.

$$
\begin{gathered}
\text { Mass wear rate }=m / t(\mathrm{mg} / \mathrm{min}) \\
\text { Volume wear rate }=V / t\left(\mathrm{~mm}^{3} / \mathrm{min}\right) \\
\text { Wear coefficient }(k)=(V \times H) /(N \times S)
\end{gathered}
$$

\section{Results and discussion}

The experimental results and polynomial-fitted curves of the wear behavior of the aluminum metallic
Table 7 Computed tribological parameters of the aluminum pin. The error limit is \pm 0.1 .

\begin{tabular}{lcc}
\hline \multicolumn{1}{c}{ Parameter } & Helix $(100 \%)$ & $\begin{array}{c}\text { Helix }(90 \%)+ \\
\text { Polytron }(10 \%)\end{array}$ \\
\hline Wear & $70 \mu \mathrm{m}$ & $20 \mu \mathrm{m}$ \\
Mass-wear rate & $3.33 \times 10^{-3} \mathrm{mg} / \mathrm{min}$ & $8.33 \times 10^{-4} \mathrm{mg} / \mathrm{min}$ \\
Volume-wear rate & $1.28 \times 10^{-3} \mathrm{~mm}^{3} / \mathrm{min}$ & $6.08 \times 10^{-5} \mathrm{~mm}^{3} / \mathrm{min}$ \\
Coefficient of friction & 0.012 & 0.004 \\
Wear coefficient $(k)$ & & $4.22 \times 10^{-11} \mathrm{~m}^{2} / \mathrm{N}$ \\
Total mass loss & $0.7992 \mathrm{mg}$ & $0.1992 \mathrm{mg}^{2}$ \\
& $($ in $240 \mathrm{~min})$ & $\left(\right.$ in $\left.240 \mathrm{~min}^{2}\right)$ \\
Total volume loss & $\begin{array}{l}0.3079 \mathrm{~mm} \\
\text { (in } 240 \mathrm{~min})\end{array}$ & $\begin{array}{c}0.01459 \mathrm{~mm} \\
\text { (in } 240 \mathrm{~min})\end{array}$ \\
\hline
\end{tabular}

pin in the AHS and APS configurations are portrayed in Figs. 2 and 3. The wear curves have been plotted with respect to time and sliding distance as well. Moreover, it is evident from these curves that Polytron provides an outstanding wear relief in the system comprising the aluminum pin on a steel disk. From the graphs, it can be anticipated that the wear in the AHS configuration is approximately $70 \mu \mathrm{m}$, whereas in the APS configuration the wear stands nearly at $20 \mu \mathrm{m}$. Then, for the same two configurations, the progress of the coefficient of friction with reference to time as well as sliding distance has been plotted and is shown in Figs. 4 and 5. The experimental conditions for the adopted configurations were all the same. One can easily notice that in the AHS conformation the introductory value of the friction coefficient is almost zero and increases almost linearly to a value of 0.012 in a time span of $100 \mathrm{~min}$ of rubbing. After that, it remains almost constant for the remaining of the experimental time. On the other hand, in the APS arrangement, the coefficient of friction starts from a value of 0.005 and then declines to a value of 0.004 . It is recognizable that Polytron reduces the wear of the pin in a significant way which, in effect, is more than a factor of three. It is found that our findings are significantly better than the research findings of other researchers done on various additives. With Polytron additive, we may predict that wear and friction reductions are admirably more pronounced than that found by Chowdhury and Khalil [40]. In addition, our findings are far better than the results shown by Miroslav and Slobodan [41], Riyadh et al. [42], and 


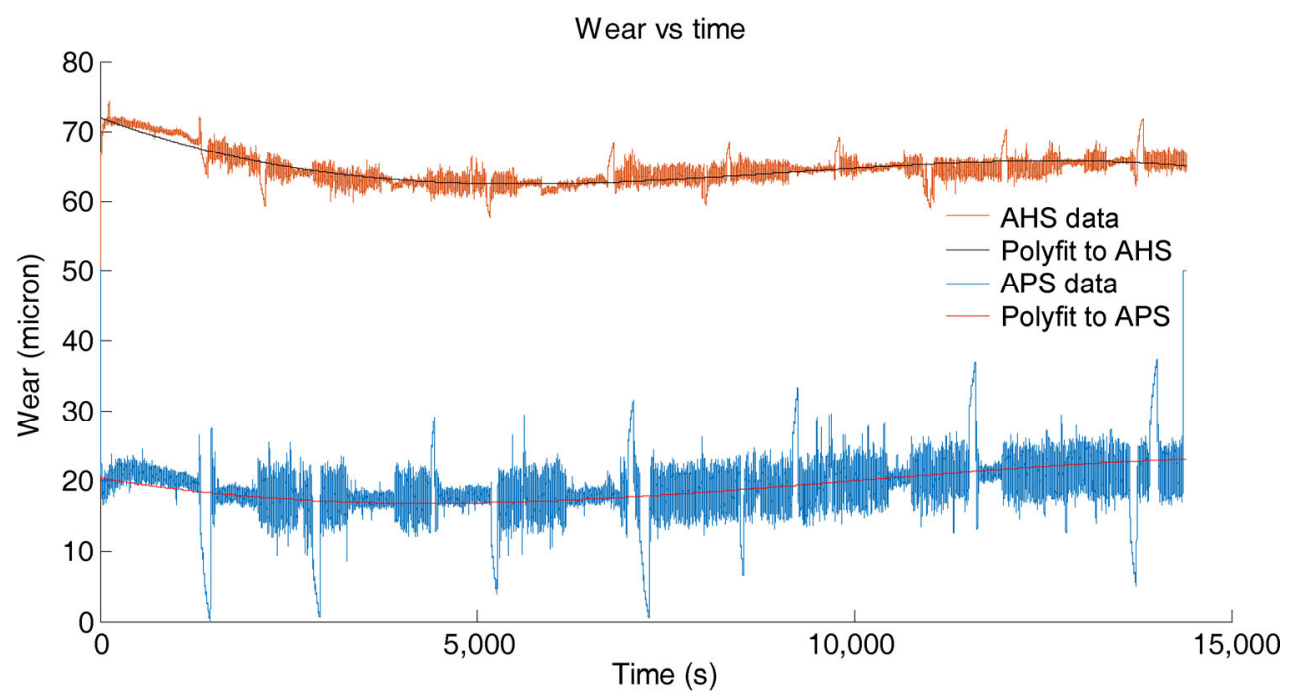

Fig. 2 Comparison plot of the wear of aluminum against time for the base oil helix and the additive (polytron); the apportioned time for both the experiments was $240 \mathrm{~min}$. Graph illustrates both the actual variation and polynomial-fitted trend of the data points.

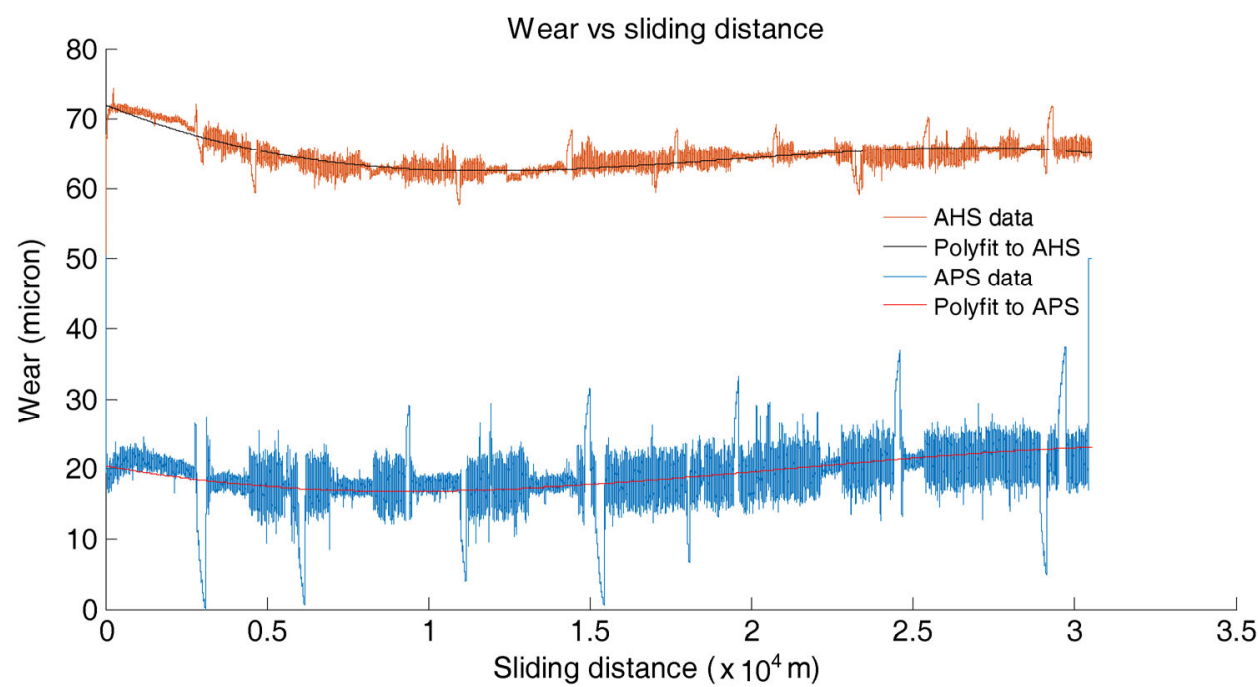

Fig. 3 Comparison plot of the wear of aluminum against sliding distance for the base oil helix and the additive (polytron); the sliding distance for both the experiments was fixed at $30.163 \mathrm{~km}$. Graph illustrates both the actual variation and polynomial-fitted trend of the data points.

Bhushan and Kulkarni [43] in their experimental judgments. The mass and volume losses of the aluminum pin were also probed in both the configurations. The comparison curves for the mass losses are shown in Figs. 6 and 7, whereas the comparison curves for the volume losses are depicted in Figs. 8 and 9. To elucidate the influence of the additive, the graphs were drawn both with respect to time and sliding distance as well. The contrast is very clear and prominent in the two types of configurations. Without additive, the two types of losses are considerably larger and increase in direct proportion with the passage of time and/or with the coverage of sliding distance. Contrariwise, the additive reduces both losses by orders of magnitude; reasonably, the losses are significantly small in the presence of the Polytron additive. This suggests a strong interaction of the lubricating medium with the steel surface in the presence of Polytron which, in turn, points to a conspicuous reduction in the wear scar of the aluminum 


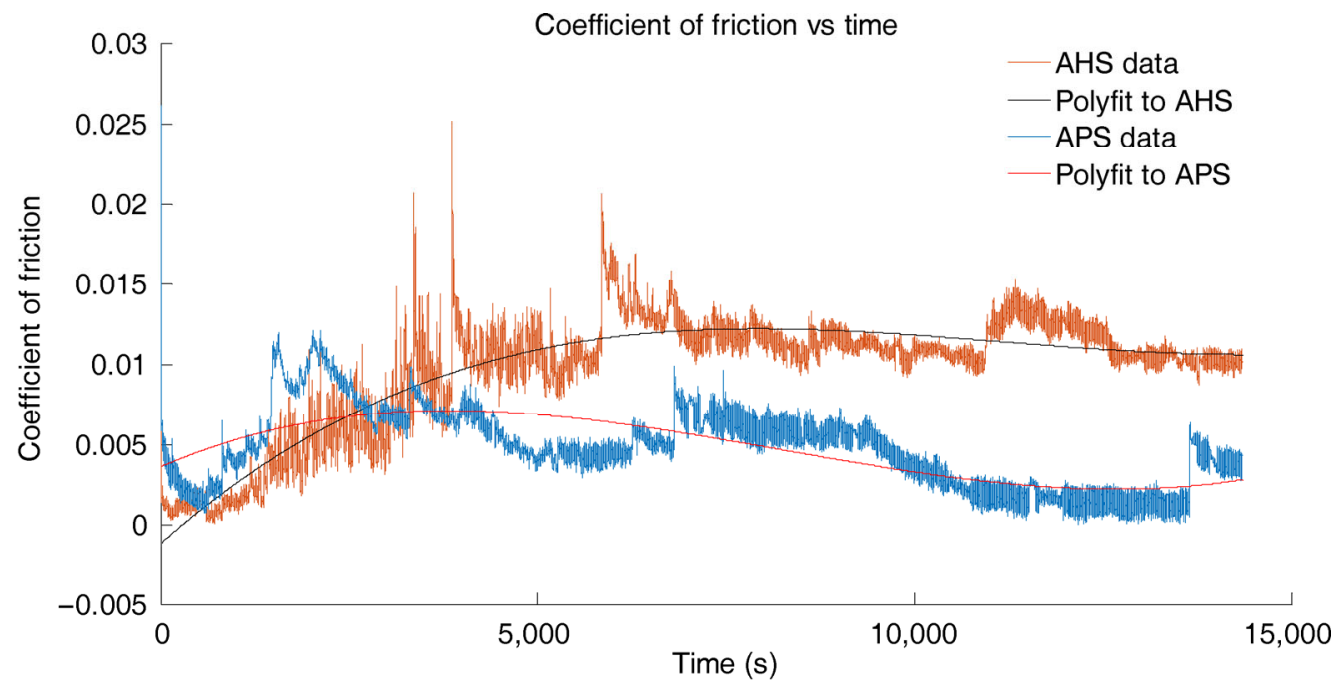

Fig. 4 Comparison plot of the coefficient of friction of aluminum against time for the base oil helix and the additive (polytron); the allocated time for both the experiments was fixed at $240 \mathrm{~min}$. Graph illustrates both the actual variation and polynomial-fitted trend of the data points.

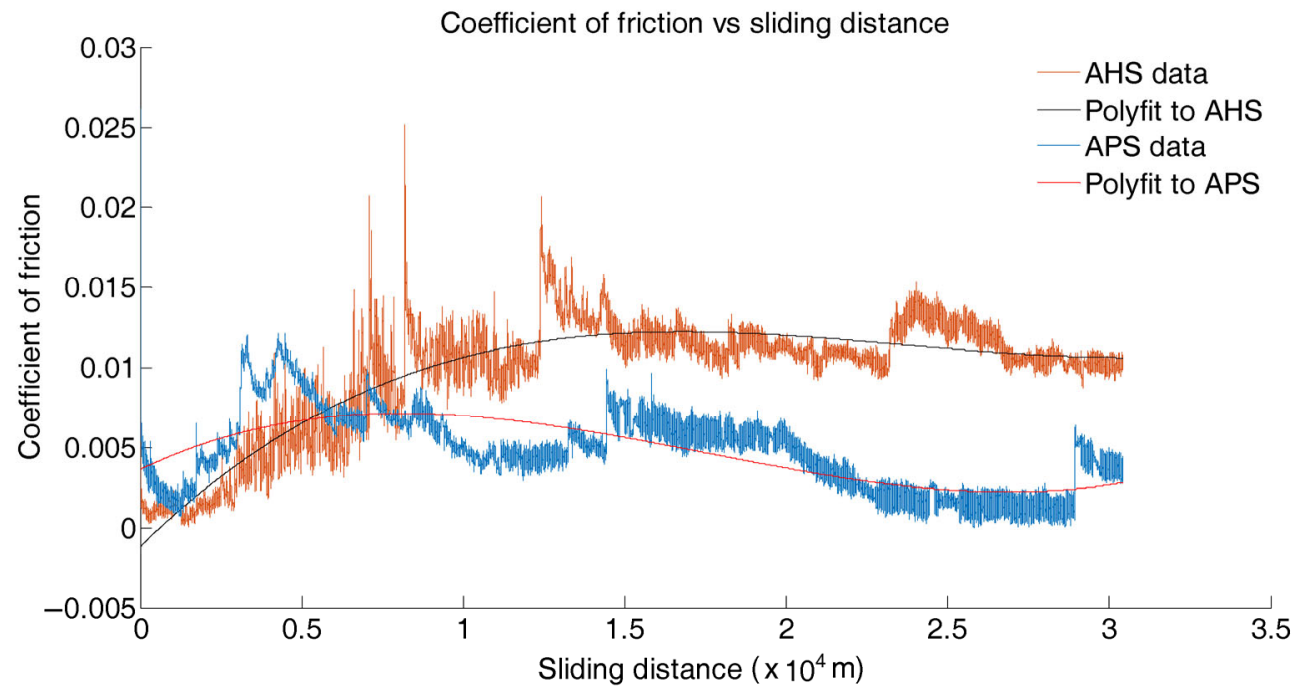

Fig. 5 Comparison plot of the coefficient of friction against sliding distance for the base oil helix and the additive (polytron); the sliding distance for both the experiments was fixed at $30.161 \mathrm{~km}$. Graph illustrates both the actual variation and polynomial-fitted trend of the data points.

metal and the prospective use of Polytron as an antiwear additive. Friction is extensively reduced and wear is significantly curtailed that shall maximize the equipment life and performance and, in turn, will aid the oil and fuel economy. This observation with the Polytron additive is quite contrary to the high wear rate results of other researchers like Suarez et al. [44] who studied the popular ZDDP additive in mineral oil stock and Ghose et al. [45] who studied TCP and found considerably higher wear rates in their findings.
By the same token, our research revelations in the APS configuration have produced better improved values for the friction coefficient, wear, and other tribological parameters than the conclusions of Anand et al. [46] who used phosphonium ionic liquid additives in diesel engine lubricants. Besides, our experimental judgments on wear and friction waning with Polytron additive are even far superior to the findings of Chen et al. [47] and Abdullah $[48,49]$ for nanoadditives in different lubricating media. This suggests that Polytron is 


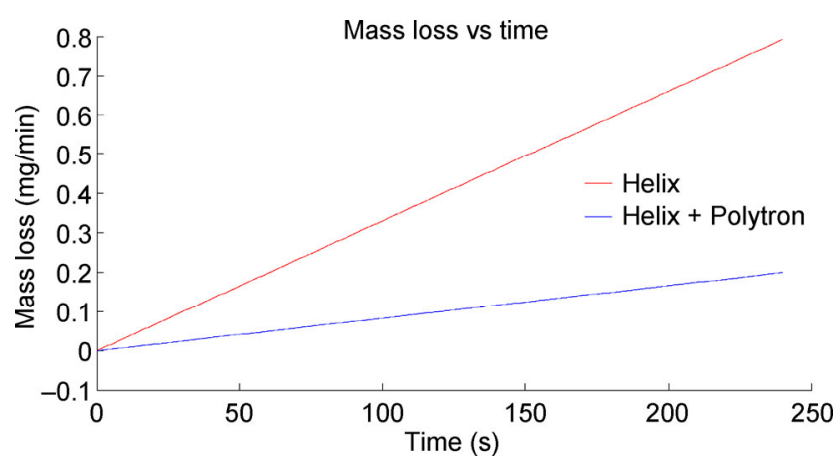

Fig. 6 Comparison plot of the mass loss against time for the base oil helix and the additive (polytron); the allocated time for both the experiments was fixed at $240 \mathrm{~min}$. Graph illustrates the actual variation of the data points.

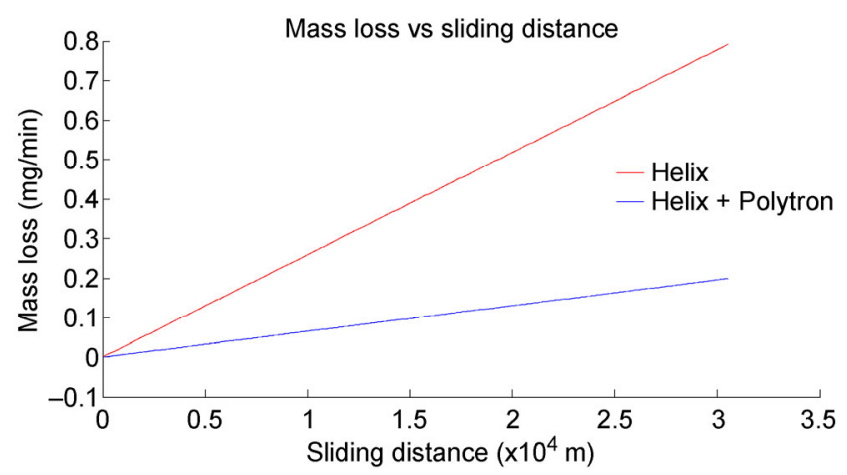

Fig. 7 Comparison plot of the mass loss against sliding distance for the base oil helix and the additive (polytron); the sliding distance for both the experiments was fixed at $30.161 \mathrm{~km}$. Graph illustrates the actual variation of the data points.

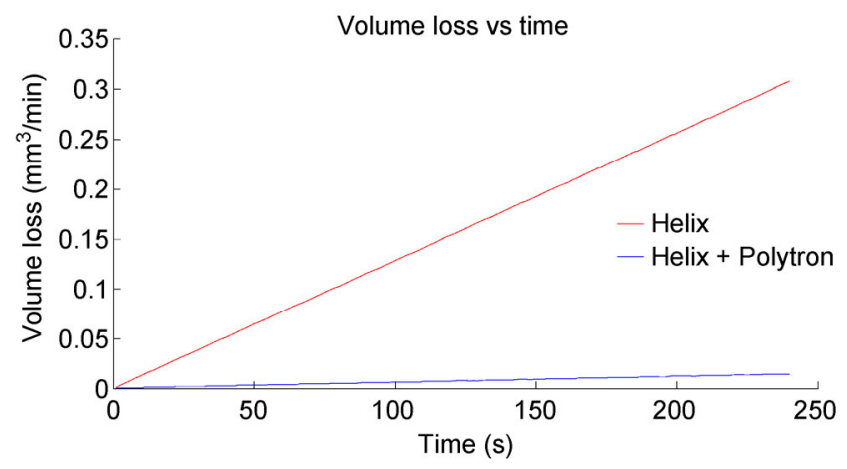

Fig. 8 Comparison plot of the volume loss against time for the base oil helix and the additive (polytron); the allocated time for both the experiments was fixed at $240 \mathrm{~min}$. Graph illustrates the actual variation of the data points.

protecting the surfaces, probably by forming a hardly adsorbed layer on the surfaces due to its ionic nature. It is expected that Polytron will adsorb on polar steel surfaces due to its own polar character, thereby protecting the surfaces against wear, and it is this

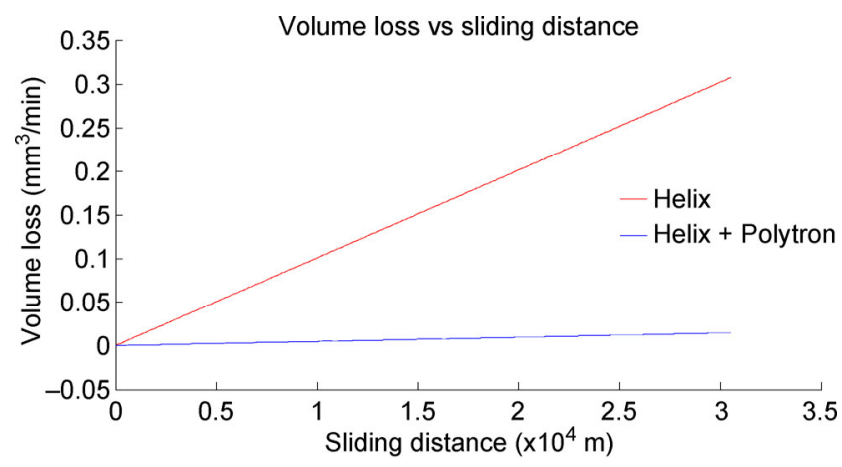

Fig. 9 Comparison plot of the volume loss against sliding distance for the base oil helix and the additive (polytron); the sliding distance for both the experiments was fixed at $30.161 \mathrm{~km}$. Graph illustrates the actual variation of the data points.

protective layer that finally breaks down the resistive force of friction between the contacting surfaces. Finally, it can be easily concluded from the calculations presented in Table 7 that Polytron declines the rate of both mass as well as volume losses of the aluminum pin by an order of magnitude. The data altogether exposes the fact that the Polytron additive substantially cuts the wear of the aluminum surface and minimizes the friction between the contacting surfaces which may be related to its ability to impregnate the surface of the aluminum metal crystal structure and the consequent adherence to the metallic surface as an unbreakable surface film.

\section{Conclusions}

The wear of the aluminum metal surface in the AHS configuration was found to be circa $70 \mu \mathrm{m}$. Nevertheless, working with $10 \%$ by volume of Polytron additive in the APS configuration, all the same, the value of wear declined to $20 \mu \mathrm{m}$ characteristic of more than twothird decrement in the wear. Likewise, the mass wear rate of the metal in the AHS mode was estimated at $3.3 \times 10^{-3} \mathrm{mg} / \mathrm{min}$ which decreased by an order of magnitude in the APS mode to a value of $8.33 \times 10^{-4}$ $\mathrm{mg} / \mathrm{min}$. The curves for the coefficient of friction in the AHS mode exhibited a value of 0.012 for the friction coefficient which diminished to a remarkably low value of 0.004 in the APS mode. It can be asserted that Polytron is an effective antiwear additive in the Helix base oil and can intrinsically reduce friction and wear by orders of magnitude. 


\section{Acknowledgments}

The authors wish to acknowledge the cooperation of the Tribology Laboratory of UMK Malaysia for the experimental work done. Besides, the Computational Lab of Yanbu Research Center Yanbu Al Sinayiah KSA is gratefully acknowledged.

\section{Nomenclature}

$m \quad$ Worn out mass of the aluminum pin in $\mathrm{mg}$

$t \quad$ Time span of the experiment in minutes

$V \quad$ Worn out volume of the aluminum pin in $\mathrm{mm}^{3}$

$\mathrm{H} \quad$ Hardness of the sliding pin

N Normal load

$S \quad$ Sliding distance in $\mathrm{m}$

AHS Configuration of the aluminum pin vs. helix-on-steel disk

APS Configuration of the aluminum pin vs. $10 \%$ polytron plus $90 \%$ helix-on-steel disk

AW Antiwear

EP Extreme pressure

MTC Metal treatment concentrate

$F_{\mathrm{N}} \quad$ Normal force (load)

$F_{\mathrm{R}} \quad$ Resistive force (friction)

TCP Tricresyl-phosphate

ZDDP Zinc dialkyl-diethylthiophosphate

Open Access: The articles published in this journal are distributed under the terms of the Creative Commons Attribution 4.0 International License (http:// creativecommons.org/licenses/by/4.0/), which permits unrestricted use, distribution, and reproduction in any medium, provided you give appropriate credit to the original author(s) and the source, provide a link to the Creative Commons license, and indicate if changes were made.

\section{References}

[1] Tung S C, McMillan M L, Automotive tribology overview of current advances and challenges for the future. Tribol Int 37: 517-536 (2004)

[2] Bermúdez M D, Jiménez A E, Sanes J, Carrión F J. Ionic liquids as advanced lubricant fluids. Molecules 14: 2888-2908 (2009)
[3] Qu J, Luo H, Chi M, Ma C, Blau P J, Dai S. Comparison of an oil-miscible ionic liquid and ZDDP as a lubricant antiwear additive. Tribol Int 71 88-97 (2014)

[4] Otero I, López E R, Reichelt M, Villanueva M, Salgado J, Fernandez J. Ionic liquids based on phosphonium cations as neat lubricants or lubricant additives for a steel/steel contact. ACS Appl Mater Interfaces 6(15): 13115-13128 (2014)

[5] Totolin V, Minami I, Gabler C, Brenner J, Dörr N. Lubrication mechanism of phosphonium phosphate ionic liquid additive in alkylborane-imidazole complexes. Tribol Lett 53: 421432 (2014)

[6] González R, Battez A H, Viesca J, Higuera-Garrido A, Fernández-González A. Lubrication of DLC coatings with two tris (pentafluoroethyl) trifluorophosphate anion-based ionic liquids. Tribol Trans 56: 887-895 (2013)

[7] Viesca J, García A, Battez A H, González R, Monge R, Fernández-González A. FAP anion ionic liquids used in the lubrication of a steel-steel contact. Tribol Lett 52: 431-437 (2013)

[8] Battez A H, González R, Viesca J L, Blanco D, Asedegbega E, Osorio A. Tribological behavior of two imidazolium ionic liquids as lubricant additives for steel/steel contacts. Wear 266: 1224-1228 (2009)

[9] Blanco D, González R, Hernández B A, Viesca J, Fernández G A. Use of ethyl-dimethyl-2-methoxyethylammonium tris (pentafluoroethyl) trifluorophosphate as base oil additive in the lubrication of TiN PVD coating. Tribol Int 44: 645-650 (2011)

[10] Yu B, Bansal D G, Qu J, Sun X, Luo H, Dai S. Oil-miscible and noncorrosive phosphonium-based ionic liquids as candidate lubricant additives. Wear 289: 58-64 (2012)

[11] Tabor D. Friction and wear-Developments over the last 50 years. In Proceedings of the International Conf. Tribology-Friction, Lubrication and Wear, 50 Years, London, 1987: 157-172.

[12] Saka N, Liou M J, Suh N P. The role of tribology in electrical contact phenomena. Wear 100: 77-105 (1984)

[13] Bhushan B. Principle and Applications of Tribology. New York: John Wiley \& Sons, Inc. 1999: 344-430.

[14] Bhushan B. Handbook of Micro/Nanotribology, 2nd ed. Boca Raton, Florida: CRC Press. 1999.

[15] Bakunin V N, Suslov A Y, Kuz'mina G N, Vedeneeva L M, Parenago O P, Migdal C A, Stott P E, Topchiev A V. Surface-capped molybdenum sulphide nanoparticles-A novel type of lubricant additive. Lubr Sci 16: 207- 214 (2004)

[16] Liu Y B, Lim S C, Ray S, Rohatgi P K. Friction and wear of aluminum-graphite composites: The smearing process of graphite during sliding. Wear 159: 201-205 (1992) 
[17] Zhang L, Chen L, Wan H, Chen J, Zhou H. Synthesis and tribological properties of stearic acid-modified anatase $\left(\mathrm{TiO}_{2}\right)$ nanoparticles. Tribol Lett 41: 409-416 (2011)

[18] Zhang B S, Xu B S, Xu Y, Gao F, Shi P J, Wu Y X. $\mathrm{Cu}$ nanoparticles effect on the tribological properties of hydrosilicate powders as lubricant additive for steel-steel contacts. Tribol Int 44: 878-886 (2011)

[19] Cumings J, Zettl A. Low-friction nanoscale linear bearing realized from multiwall carbon nanotubes. Science 289: 602-604 (2000)

[20] Stachowiak G W, Batchelor A W. Engineering Tribology, 4th ed. Amsterdam, Netherlands: Elsevier, 2014.

[21] Quaroni L, Chumanov G. Preparation of polymer-coated functionalized silver nanoparticles. J Am Chem Soc 121(45): 10642-10643 (1999)

[22] Mandal T, Fleming M S, Walt D R. Preparation of polymer coated gold nanoparticles by surface-confined living radical polymerization at ambient temperature. Nano Lett 2(1): 3-7 (2002)

[23] Gubin S P. Metal-containing nanoparticles within polymeric matrices: Preparation, structure, and properties. Coll Surf A: Physicochem Eng Aspects 202(2): 155-163 (2002)

[24] Zhang Z, Liu W, Xue Q. Study on lubricating mechanisms of $\mathrm{La}(\mathrm{OH})_{3}$ nanocluster modified by compound containing nitrogen in liquid paraffin. Wear 218(2): 139-144 (1998)

[25] Hu Z S, Dong J X. Study on antiwear and reducing friction additive of nanometer titanium oxide. Wear 216(1): 92-96 (1998)

[26] Socrates G. Infrared Characteristics Group Frequencies. New York: John Wiley \& Son 1994.

[27] Minami I, Mori S. Anti-wear additive for ester oil. In 14th International Colloquium Tribology, 2003.

[28] Kamimura H, Kubo T, Minami Mori S. Effect and mechanism of additives for ionic liquids as new lubricants. Tribol Int 40(4): 620-625 (2007)

[29] Du L, Xu B, Dong S, Yang H, Tu W. Study of tribological characteristics and wear mechanism of nano-particle strengthened nickel-based composite coatings under abrasive contaminant lubrication. Wear 257: 1058-1063 (2004)

[30] Chowdhury M A, Helali M M. The effect of amplitude of vibration on the coefficient of friction. Tribol Int 41(4): 307-314 (2008)

[31] Bhushan B. Tribology and Mechanics of Magnetic Storage Devices $2^{\text {nd }} e d$. New York: Springer-Verlag, 1996.

[32] Belau P J. Friction Science and Technology. New York: Marcel Dekker, 1996.

[33] Adamovića D, Stefanovića M, Živkovića M, Mitrovića S, Živkovića J, Živića F. Influence of the lubricant type on the surface quality of steel parts obtained by ironing. Tribol Ind
37(2): 215-224 (2015)

[34] Ligier J L, Noel B. Friction reduction and reliability for engines bearings. Lubricant 3: 569-596 (2015)

[35] Ahmer S M H, Bahrudin M S, Abdullah S F, Jan L S. A quantitative analysis of the wear of aluminum in the presence of polytron additive in the helix lubricant. In Proceedings of the National Graduate Conference (NatGrad2012), Universiti Tenaga Nasional, Putrajaya Campus, Malaysia, EP0147, 2012.

[36] Ahmer S M H, Jan L S, The wear of aluminum in the presence of polytron additive in the helix lubricant; a quantitative analysis. CMNSEM 4(4): 278-290 (2013)

[37] John E H. Aluminum: Properties and Physical Metallurgy. Aluminum Association, American Society for Metals, 1984.

[38] Information. http://www.epc.shell.com/, 2015

[39] Information. http://www.polytron.my/about_us.html, 2012

[40] Chowdhury M A, Khalil M K, Nuruzzaman D M, Rahaman M L. The effect of sliding speed and normal load on friction and wear property of aluminum. Int J Mech Mech Eng 11(01): 45-49 (2011)

[41] Miroslav B, Slobodan M. Tribological potential of zincaluminum alloys improvement. Tribol Ind 31(1\&2): 15-28 (2009)

[42] Riyadh A, Al-Samarai, Haftirman, Khair-el-Rafezi Ahmad Y, Al-Douri. Effect of load and sliding speed on wear and friction of aluminum-Silicon casting alloy. Int J Sci Res Publ 2(3): (2012)

[43] Bhushan B, Kulkarni A V. Effect of normal load on microscale friction measurements. Thin Solid Films 278: 49-56 (1996)

[44] Suarez A N, Grahn M, Pasaribu R, Larsson R. The influence of base oil polarity on the tribological performance of zinc dialkyl-dithiophosphate additives. Tribol Int 43: 2268-2278 (2010)

[45] Ghose H M, Ferrante J, Honecy F S. The effect of tricresylphosphate (tcp) as an additive on wear of iron (Fe). NASA TM-100103 (1987)

[46] Anand M, Hadfield M, Viesca J L, Thomas B, Hernández Battez A, Austen S. Ionic liquids as tribological performance improving additive for in-service and used fully-formulated diesel engine lubricants. Wear 334: 67-74 (2015)

[47] Chen S, Liu W M, Yu L G. Preparation of DDP-coated PbS nanoparticles and investigation of the antiwear ability of the prepared nanoparticles as additive in liquid paraffin. Wear 218(2): 153-158 (1998)

[48] Abdullah S F. Nanoparticle (capped wolfram (VI) oxide) as additive in lubricant. ICCBT 32: 347-356 (2008)

[49] Abdullah S F. Study on nanoparticles as an additive in lubricant towards sustainability of energy in industrial engineering. $J$ Energy Environment 1: 34-37 (2009) 


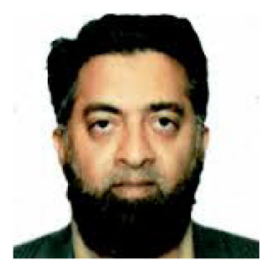

Syed Mohammad Hasan AHMER. He received his master degree in physics in 1992 from the University of Karachi, Pakistan. Currently he is a Ph.D. student in the University Malaga International (UMA), Spain. $\mathrm{He}$ is

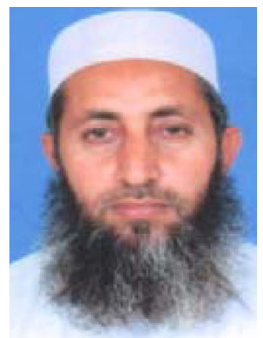

Lal Said JAN. He received his M.S. degree in physics in 1990 from the University of Peshawar, Pakistan. He received his $\mathrm{Ph} . \mathrm{D}$. degree in 2006 from the Department of Applied Physics, National University of Malaysia (UKM), pursuing his Ph.D. studies at the Department of Mechanical Engineering. $\mathrm{He}$ is a lecturer of physics at the Royal Commission of Yanbu Colleges and Institutes (RCYCI), Saudi Arabia. His research interests include friction, wear, and lubrication.

Malaysia. During his Ph.D. studies, he did research on nano-structured polymers and ceramics. He is an assistant professor of physics at the Royal Commission of Yanbu Colleges and Institutes (RCYCI), Saudi Arabia. His current research interest is tribology of nano-structured materials. 